\title{
The Role of Sport Involvement and General Self-Worth in the Interplay between Body Dissatisfaction, Worry, and School Disaffection in Preadolescent Boys and Girls
}

\author{
Diana Raufelder, ${ }^{1}$ Sandra Waak, ${ }^{1}$ Alice Melchior, ${ }^{1}$ and Angela Ittel ${ }^{2}$ \\ ${ }^{1}$ Free University Berlin, Department of Educational Science and Psychology, AB Methods and Evaluation, \\ Habelschwerdter Allee 45, 14195 Berlin, Germany \\ ${ }^{2}$ Institute of Technology Berlin, Educational Psychology, Department of Educational Science, Marchstraß 23, 10587 Berlin, Germany
}

Correspondence should be addressed to Diana Raufelder; diana.raufelder@fu-berlin.de

Received 7 April 2013; Accepted 18 July 2013

Academic Editor: Lei Chang

Copyright (C) 2013 Diana Raufelder et al. This is an open access article distributed under the Creative Commons Attribution License, which permits unrestricted use, distribution, and reproduction in any medium, provided the original work is properly cited.

\begin{abstract}
While in recent years there has been increasing research on body dissatisfaction in preadolescence and a small body of research on worry in association with eating disorders, less is known about their effects on school disaffection. Therefore, the current study examined possible gender-specific relations between body dissatisfaction, worry, and school disaffection. To identify possible strategies of intervention and prevention, sport involvement and general self-worth were tested as mediators. Multigroup structural equation modeling (SEM) was used to test for the mediating role of sport involvement and general self-worth in the association between body dissatisfaction, worry, and school disaffection in a sample of 4 th, 5 th, and 6 th grade students $\left(n=167 ; M_{\text {age }}=10.3\right)$ in elementary schools in Berlin, Germany. The results suggest that promoting feelings of general self-worth could be an effective starting point in decreasing the association between body dissatisfaction, worry, and school disaffection, in both boys and girls. Conversely, sport involvement was identified as a mediating factor for boys only.
\end{abstract}

\section{Introduction}

A growing number of young boys and girls report feeling dissatisfied with their bodies and having a negative body image and self-judgments which are typically associated with negative emotions, particularly feelings of worry [1-3]. Actually, Sassaroli and colleagues have shown that there is a psychopathological association between worry and eating disorders in clinical samples [4]. As both worry and body dissatisfaction develop, increase, and manifest during adolescence, particularly for girls $[1,5-8]$, it is critical that preadolescents receive preventive and sustainable health promotion. In addition, school disaffection and a decrease in school achievement are also common in preadolescence for both boys and girls [9].

As Fredrickson's $[10,11]$ broaden and build theory postulates, the experience of frequent positive emotions serves to broaden humans' thoughts and behaviors. Based on this theory, the study of Reschly and colleagues with students from secondary schools has shown that frequent positive emotions during school were associated with higher levels of student engagement and negative emotions with lower levels of engagement [12]. According to Reschly et al. and based on the reverse of Frederickson's broaden and build theory, the main goal of the present study was to examine if negative emotions and thoughts, specifically worry and body dissatisfaction, are associated with school disaffection in preadolescence considering potential gender-specific differences. Within the following paragraphs, the empirical and theoretical background of these variables will be discussed in detail.

\section{Health Risks on the Rise for Children in Western Cultures}

In Western societies, there are an alarming number of children and adolescents who are overweight or obese. A longitudinal German study has shown that these numbers have increased by $50 \%$ since the 1990s [13]. In the United States of 
America (USA), 30\% of all children are already overweight [14]. During the last ten years, the number of overweight children in the USA has increased by approximately $30 \%$ [14]. At the same time, pervasive media reinforcement of the thin standard of beauty [15] has created a breeding ground for epidemic levels of body image dissatisfaction and unhealthy eating behaviors. Irving and Berel [16] call this epidemic the "thinning" of Western beauty ideals. As a consequence, there is a growing amount of children and adolescents who have developed eating disorders (e.g., anorexia nervosa and bulimia nervosa) [17-19]. Historically, much of the research on eating disorders has focused on females because of the dramatic rise in body dissatisfaction following the onset of puberty among girls [20]. Additionally, there is a greater sociocultural emphasis on appearance and thinness for females [21, 22]. However, since androgyny and muscular male body images have become popular, research has indicated that eating disorders and body dissatisfaction are present among preadolescent and adolescent boys as well $[6,23,24]$. There are increasing numbers of boys with eating disorders [17] as well as with extreme muscle-building behavior, which is often associated with the intake of healthrisking and/or illegal muscle-building substances and Body Dysmorphic Disorder (BDD) [25-28]. For both genders, the desire to alter body shape or weight is common $[29,30]$ and is associated with emotional distress [31] psychiatric disturbances such as depression [32-34] as well as eating disorders $[35,36]$.

The motives for these health-risking behaviors are complex and cannot be attributed to a single cause. Internal aspects (e.g., inner-psychological processes) as well as external aspects (e.g., beauty ideals, media influence, and nutrition balance) are both part of this process. Nevertheless, the above mentioned body dissatisfaction (i.e., determined by the discrepancy between perceived body image and ideal body image) can be understood as an important determinant in this process, as it is often the foundation for poor eating, dieting, and reduced physical activity [37].

Research has demonstrated that girls tended to maintain their rank in weight concerns and body dissatisfaction across ages 5 to 9 years [38]. An experimental study conducted by Harriger et al. [39] with three- to five-year-old girls in Kindergarten revealed that even girls in this young age group are convinced that "thinner is better". For girls, this attitude becomes especially problematic during adolescence, when the female body develops in a manner contrary to the modern skinny beauty ideal. Boys, on the other hand, often perceive their bodily changes (i.e., more muscles) as a positive experience [5].

\section{The Development of Body Dissatisfaction and Worry in Adolescence}

Adolescence is characterized by change across many aspects of life: physical, social, and emotional [40]. Furthermore, the body becomes essential to adolescents' shifting identity. In general, adolescent girls are more dissatisfied with their bodies and are more self-critical than boys [5-7, 21, 41]. Additionally, the influence of the media on body satisfaction seems to be stronger for girls than for boys [42]. This fact can be explained by the cultural emphasis on judging women strictly in terms of their physical appearance and for women's conformity to standards of beauty and fashion [21]. As girls' physical development progresses, their dissatisfaction with their body increases. Girls report being most dissatisfied with their hips and thighs [43]. Following the standards of present beauty ideals, girls' body satisfaction increases the thinner they are [44].

Although boys show higher mean levels of body satisfaction during early adolescence than girls (e.g., $[20,45,46]$ ), many boys also experience body dissatisfaction and often report dietary changes in the hope to become bigger and more muscular [47-49]. Boys' body dissatisfaction manifests either in being too thin or too large. Between the ages of 13 and 18, boys become continuously more satisfied with their body, while the satisfaction of girls during this time steadily decreases [20].

As part of the emotional changes, adolescence is determined by rapid shift moods, vacillating between happiness and distress, and self-confidence and worry. Worry is characterized by the predominance of negative thoughts, which means that worrying people repeatedly think a lot about possible negative events they are afraid of, potential future threats, risks, uncertainties, and imagined catastrophes [50, 51]. In the framework of cognitive research, worry as a mental process is well studied as a main feature of anxiety [52], and it is the central feature of generalized anxiety disorder as defined by DSM-IV [53]. However, there is only a small body of research devoted to the association between worry and eating disorders [4]. Wadden et al. [3] investigated different kinds of worry in nonclinical adolescents and found that girls showed higher worry levels about weight and food than boys. In addition, Sassaroli and Ruggiero [2] found that in a stressful situation, worry is related to the Eating Disorders Inventory's subscales in nonclinical subjects as well. Finally, the findings of Sassaroli et al. [4] suggest that worry is important for understanding the psychopathology of eating disorders. As body dissatisfaction is a robust risk factor of eating disorders [54], it might be essential to examine the association between worry and body dissatisfaction as well. As an extension of these above mentioned findings, the present study aimed to examine if worry is present in preadolescence already and if it may play a role in body dissatisfaction and school disaffection.

\section{School Context as a Place of Personal Development}

Preadolescents do not only spend an increasing amount of time at school; their personal development, academic achievement, social relationships, and motivation are interwoven aspects of daily life at school. Therefore, the assumption that internal and external changes during preadolescence are associated with students' emotional and behavioral school engagement is self-evident.

According to the model by Connell and his colleagues [55-57], engagement and disaffected patterns of action are two ends of a continuum. While engaged students show 
TABle 1: Sample.

\begin{tabular}{|c|c|c|c|c|c|c|c|c|}
\hline & \multicolumn{2}{|c|}{ Sample total } & \multicolumn{2}{|c|}{ 4th grade } & \multicolumn{2}{|c|}{ 5th grade } & \multicolumn{2}{|c|}{ 6th grade } \\
\hline & Male & Female & Male & Female & Male & Female & Male & Female \\
\hline$N$ & 90 & 77 & 18 & 28 & 63 & 31 & 9 & 18 \\
\hline$N_{\text {total }}$ & \multirow{2}{*}{\multicolumn{2}{|c|}{$\begin{array}{c}167 \\
8-12\end{array}$}} & \multicolumn{2}{|c|}{46} & \multicolumn{2}{|c|}{94} & \multicolumn{2}{|c|}{27} \\
\hline Age & & & & & & & & \\
\hline
\end{tabular}

behavioral involvement in learning and a positive emotional tone $[55,56]$, disengaged or disaffected students are passive, do not make an effort in class, are bored, give up easily, and display negative emotions such as anger, blame, and denial [57]. In other words, engagement in school can be defined as including both psychological and behavioral components $[58,59]$. Therefore, as the tradition in research on school engagement has shown $[58,60]$, school engagement is consistently predictive of academic achievement [61] across all demographic variables (e.g., gender, race, ethnicity, socioeconomic status). In contrast, school disaffection often leads to truancy and school dropout [57]. Behaviorally, disaffected children are passive, do not make a lot of effort, and give up easily when faced with challenges. Emotionally, disaffected children can be bored, depressed, and anxious. Furthermore, they perceive anger about their presence in the classroom, can be withdrawn, shy away from learning opportunities, or behave rebelliously toward teachers and classmates [57].

\section{Sport Involvement and General Self-Worth as Mediators}

As mentioned above, the phase of preadolescence becomes essential if we want to protect girls and boys from developing school disaffection, body dissatisfaction, and worry. To identify possible strategies of intervention and prevention, sport involvement and general self-worth were tested as mediators.

While several studies have found that there is a negative association between general self-worth and body dissatisfaction for both females [62] and males [63, 64], boys typically show higher levels of general self-worth [65-67]. Additionally, there is a negative association between general self-worth and worry [68]. In other words, a high general self-worth might protect the development of both body dissatisfaction and worry in preadolescence. This is based on the idea that global self-worth is usually considered as a central parameter in psychological health and positive development [69].

Furthermore, studies on sport involvement have shown that playing sport benefits not only the physical development but also the emotional well-being of children [70, 71]. Children who regularly play sport show less emotional and behavioral conspicuity [72]. There is strong evidence for the enhancement of children's self-esteem through participation in sport and physical activity $[73,74]$. In addition, physical activities are associated with enhanced mood and affect [70, $75,76]$ and are able to decrease depressive symptoms [77]. A small number of studies have shown that sport involvement has positive effects in terms of school achievement [78] and attitudes towards school as well [79-82].

\section{Current Study}

The current study examined the relationship between body dissatisfaction, worry, and (emotional and behavioral) school disaffection, mediated by general self-worth and sport involvement. In detail, based on Fredrickson's [10, 11] broaden and build theory and the empirical findings outlined above, the current study examined the following three hypotheses (1) Based on the current research, it was hypothesized that there would be an association between body dissatisfaction, worry, general self-worth, sport involvement, and school disaffection. In detail, we expected that body dissatisfaction and worry would positively correlate with school disaffection, whereas sport involvement, and general self-worth would negatively correlate with school disaffection. Furthermore, we hypothesized positive correlations between worry and body dissatisfaction. (2) In addition, it was hypothesized that body dissatisfaction and worry would negatively predict general self-worth and sport involvement. In addition, general self-worth and sport involvement were tested as negative predictors of school disaffection. (3) Based on the positive benefits of general self-worth and sport involvement, it was hypothesized that general self-worth and sport involvement would mediate the relationship between body dissatisfaction, worry, and emotional/behavioral school disaffection (baseline model). Given that boys' self-worth and emotional mood is more positive and more constant compared to girls, and that many boys report trying to alter their body [83] by engaging in sport [42], it was hypothesized that the relationship between the included variables in the baseline model would differ for boys and girls in preadolescence.

\section{Method}

7.1. Participants. The participants $(N=167)$ were 8 - to 12 year-old 4 th, 5 th, and 6 th grade students $\left(M_{\text {age }}=10.33\right.$ years; $\mathrm{SD}=.81)$ in elementary schools in Berlin, Germany. Approximately $53.9 \%$ of the students were boys $(n=90)$ and $46.1 \%$ were girls $(n=77)$ (see Table 1$)$. As previous research has shown, socioeconomic status (SES) is not related to the prevalence of eating problems. In one study, no significant differences in body dissatisfaction and eating behaviors between participants with high, middle, and low SES were found [84]. Furthermore, according to Gibbons [85], recent studies working with large heterogeneous samples have not found a relation between eating disorders and differences in SES.

7.2. Procedure. Data was collected during the spring terms of 2010 from two elementary schools in middle/upper SES neighborhoods. For each participating class, data was collected during a four-week period. There were a total of six 
measurement points (MPs). The children filled out two questionnaires (2 MPs), one at the beginning of the four-week period and one at the end of the four-week period. During this period, student kept a health diary, which included weekly reporting throughout one month on eating behavior, spare time behavior (e.g., sport), and emotional mood (e.g., worry) (4 MP). Parental permission for student participation was obtained through a process of active consent. The researchers thoroughly explained the questionnaires to the students and gave instructions on how to complete the measures, in particular, the meaning of the Likert scales and the health diary. The two questionnaires assessed body dissatisfaction, general self-worth, and school disaffection, whereas sport involvement and worry were assessed through the health diary. As a part of each testing session, participants received uniform information about the nature of the study and what they were required to do. Participants were informed that there were no right or wrong answers and they were free to discontinue their participation at any stage. All questionnaires were arranged in random order to avoid order effects. Finally, students were informed that all of their answers would be confidential and that they were not obliged to answer any of the questions.

\section{Measures}

8.1. Body Dissatisfaction. Participants were asked about the negative perception of their own body by using the body dissatisfaction scale from Garner et al. [86] (e.g., "I would like my body to be different") ( $\alpha=.84)$. Items were rated on a five-point Likert scale ranging from 1 = "strongly disagree" to 5 = "strongly agree."

8.2. Worry. By using a single item measure, participants were asked about their feelings of worry during the last seven days at four measurement points (e.g., "Over the last 7 days, I have felt worried") ( $\alpha=.71)$. Responses were scored on a five-point Likert scale ranging from $1=$ "not at all" to $5=$ "extremely." The test-retest reliability was statistically satisfying $(\alpha=.73)$. For the following statistical analyses, the average value of the four measurement points was used.

8.3. Sport Involvement. In their health diary, participants provided information at four measurement points about whether they played sport after school (e.g., "Yesterday when I got home from school, I played sport") ( $\alpha=.77)$. The single item measure was based on a dichotomous scale $(0=$ "no", $1=$ "yes"). Again, the test-retest reliability was statistically satisfying $(\alpha=.78)$. The average value of the four measurement points was used in the following statistical analyses.

8.4. General Self-Worth. General self-Worth was measured with a scale developed by Harter [87]. Participants read statements and indicated how well these described themselves (e.g., "I am happy with who I am" or "I am sure of myself") ( $\alpha=.75)$. Items were rated on a five-point Likert scale ranging from 1 = "strongly disagree" to 5 = "strongly agree."
8.5. Emotional School Disaffection. Based on the work of Skinner et al. [88], participants read statements and answered how well these described themselves (e.g., "When I am working on my classwork, I feel mad") ( $\alpha=.75)$. Responses were measured on a five-point Likert scale ranging from $1=$ "strongly disagree" to 5 = "strongly agree."

8.6. Behavioral School Disaffection. Based on the work of Skinner et al. [88], participants gave self-referential information to statements describing negative behavior in school (e.g., "In class, I do just enough to get by") $(\alpha=.73)$. Items were rated on a five-point Likert scale ranging from $1=$ "strongly disagree" to 5 = "strongly agree."

\section{Statistical Analyses}

9.1. Structural Equation Modeling-Path Analysis. Structural equation models (SEMs) with Mplus version 6.11 [89] and maximum likelihood estimation on a correlation matrix were used to assess the theorized relations among the variables of interest. Path analysis was performed to test the mediating roles of sport involvement and general self-worth between body dissatisfaction and emotional/ behavioral school disaffection and worry and emotional/behavioral school disaffection. A multigroup structural equation model for female and male (model 2) children was run separately and was compared with the baseline model (model 1) in terms of model fit and parsimony. We conducted a bootstrapping analysis to assess the effects of mediators by constructing confidence intervals (CIs) around the estimates [90-93]. For small sample sizes that may not fulfill assumptions of normality, this nonparametric resampling approach is recommended. The null hypothesis of no direct effect is rejected if a value of 0 lies outside of the confidence interval, which allows for more stable parameter estimates $[90,91,94]$.

Model fit was estimated in Mplus using 5 primary fit indices for model fit as recommended by $\mathrm{Hu}$ and Bentler [95]: chi-square test of model fit $\left(\chi^{2}\right)$, root mean square error of approximation (RMSEA), comparative fit index (CFI), Tucker-Lewis index (TLI), and standardized root mean square residuals (SRMRs). According to Geiser [94], the $\chi^{2}$ difference test was conducted to compare the baseline model (1) to the multigroup structural equation modeling (2), as well as comparing the fit indices of the two models (see Table 4). Furthermore, we took into account the values of the determination coefficient $r^{2}$ for both models in order to consider the proportion of explained variance. To account for missing data, models were estimated with full information maximum likelihood (FIML) using Mplus version 6.11 [96].

\section{Results}

10.1. Descriptive Statistics and Intercorrelations. In the first step, intercorrelations between the variables of interest were conducted. Means, standard, deviations and ranges for the variables that were used in this study are reported in Table 2. Bivariate correlations between the variables and gender are shown in Table 3 . There was a high negative and significant 
TABLE 2: Descriptive statistics.

\begin{tabular}{lcccc}
\hline Measure & Minimum & Maximum & Mean & Std. deviation \\
\hline (1) $\mathrm{BD}^{+}$ & 1 & 5 & 2.44 & 1.25 \\
(2) Self-worth & 1 & 5 & 3.61 & 0.94 \\
(3) $\mathrm{ESD}^{++}$ & 1 & 5 & 2.20 & 0.86 \\
(4) $\mathrm{BSD}^{++}$ & 1 & 5 & 2.97 & 0.83 \\
(5) Play sport & 0 & 1 & 0.27 & 0.34 \\
(6) Worry & 1 & 5 & 1.97 & 0.88 \\
\hline
\end{tabular}

Note. ${ }^{+} \mathrm{BD}$ : body dissatisfaction; ${ }^{++}$ESD: emotional school disaffection; ${ }^{+++}$BSD: behavioral school disaffection. $N=167$.

TABLE 3: Bivariate associations between body dissatisfaction, general self-worth, school disaffection, sport involvement, worry, sadness, depression, happiness, and gender.

\begin{tabular}{lcccccc}
\hline Measure & $(2)$ & $(3)$ & $(4)$ & $(5)$ & $(6)$ & $(7)$ \\
\hline (1) $\mathrm{BD}^{+}$ & $-.59^{* *}$ & $.19^{*}$ & $.20^{*}$ & $-.18^{*}$ & $.31^{* *}$ & -.02 \\
(2) Self-worth & - & $-.43^{* *}$ & $-.22^{*}$ & $.22^{* *}$ & $-.48^{* *}$ & -.01 \\
(3) $\mathrm{ESD}^{++}$ & & - & $.47^{* *}$ & $-.22^{* *}$ & $.30^{* *}$ & .05 \\
(4) $\mathrm{BSD}^{++}$ & & & - & -.11 & $.19^{*}$ & .13 \\
(5) Play sport & & & & - & $-.27^{* *}$ & $.37^{* *}$ \\
(6) Worry & & & & & - & $-.17^{*}$ \\
(7) Gender & & & & & & - \\
\hline
\end{tabular}

Note. ${ }^{*} P<.05 ;{ }^{* *} P<.001 ; N=167 ;{ }^{+}$BD: body dissatisfaction; ${ }^{++}$ESD: emotional school disaffection; ${ }^{+++} \mathrm{BSD}$ : behavioral school disaffection; gender: $0=$ female, $1=$ male.

correlation between general self-worth and body dissatisfaction $(r=-.59, P<.001)$, worry $(r=-.48, P<.001)$, and emotional school disaffection $(r=-.43, P<.001)$. That means the higher the students' general self-worth is, the less they are dissatisfied with their body, the less they feel worried, and the less they report emotional school disaffection. There was a relatively strong and highly significant association between sport involvement and gender $(r=.37, P<.001)$ and a negative correlation between worry and gender $(r=$ $-.17, P<.001)$. In other words, boys tend to play more sport, whereas girls tend to have higher levels of worry. In addition, a negative association between sport involvement and emotional school disaffection $(r=-.22, P=.01)$ has been identified. Sport involvement negatively correlated with the variable worry $(r=-.27, P<.001)$ and with body dissatisfaction $(r=-.18, P=.03)$. That means the more students play sport, the less they feel worried and dissatisfied with their body. In addition, worry correlated positively with body dissatisfaction $(r=.31, P<.001)$.

10.2. Structural Equation Modeling. In the second step, a structural equation model was used to assess whether general self-worth and sport involvement mediate the relationship between body dissatisfaction, worry, and emotional/behavioral school disaffection in the baseline model (see Figure 1). Our analyses were guided by the ideas presented by Preacher and Hayes $[90,91]$. Their approach emphasizes the strength of the indirect effect and is not directly concerned with the statistical significance of the observed associations between predictor, mediator, and outcome.
TABLE 4: Model fit indices comparing baseline model and gender model.

\begin{tabular}{lcc}
\hline Measure & Baseline model & Gender model \\
\hline$\chi^{2}$-Test of Model Fit $\left(\mathrm{df}^{+}\right)$ & $6.42(4)$ & $10.61(8)$ \\
$P\left(\chi^{2}\right)$ & .17 & .22 \\
CFI/TLI & $.98 / .94$ & $.98 / .94$ \\
RMSEA $(90 \% \mathrm{CI})$ & $.06(.00, .14)$ & $.06(.00, .15)$ \\
$P(\text { RMSEA } \leq .05)^{++}$ & .34 & .36 \\
SRMR & .03 & .04 \\
\hline
\end{tabular}

Note $.{ }^{+} \mathrm{df}=$ degrees of freedom, ${ }^{++} \mathrm{P}(\mathrm{RMSEA})=$ Probability for RMSEAvalue $\leq .05$.

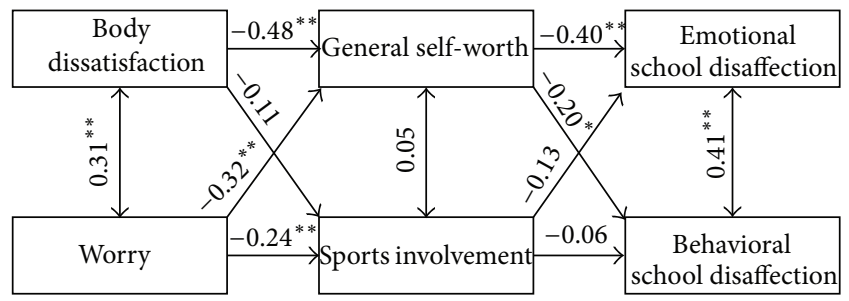

FIGURE 1: Baseline model of path analysis. Significant effects shown as standardized coefficients (betas) are noted with the symbol $\left({ }^{*} \mathrm{P}<\right.$ $\left..05 .{ }^{* *} P<.001\right)$.

Our baseline model showed a good fit (see Table 4). The determination coefficient $\left(r^{2}\right)$ was the highest for general selfworth, where the variance explained in the model was $42 \%$. For emotional school disaffection $r^{2}$ amounts to $20 \%$ and for behavioral school disaffection $r^{2}$ amounts to $4.9 \%$. Finally, the variance accounted for by sport involvement was $8.4 \%$.

10.2.1. Direct Effects. The model included direct effects of (a) body dissatisfaction on general self-worth and sport involvement and (b) worry on general self-worth and sport involvement, (c) general self-worth on emotional school disaffection and behavioral school disaffection, and (d) sport involvement on emotional school disaffection and behavioral school disaffection. All regressions of and on general self-worth were significant, whereas sport involvement only regressed on worry $(B=-.09, \beta=-.24, \mathrm{SE}=.03, P<.001)$.

The zero order correlations between the predictors and outcome variables were significant, but not between the mediators general self-worth and sport involvement.

10.2.2. Indirect Effects. As recommended by Preacher and Hayes [90, 91], we conducted bootstrapping to assess the effects of mediators by constructing CIs around the estimates. This procedure reduces bias caused by nonnormality in the sampling distribution of indirect effects [97]. Consistent with what was hypothesized, we observed significant indirect effects of body dissatisfaction on emotional school disaffection mediated by general self-worth $(B=.13, \beta=.19$, SE $=$ $.03,95 \%$ CI $[.08, .20])$. In addition, another significant indirect effect of worry on emotional school disaffection through general self-worth $(B=.13, \beta=.13, \mathrm{SE}=.04,95 \% \mathrm{CI}[.07$, .22]) was identified. We observed a similar pattern for the indirect effects of body dissatisfaction on behavioral school 


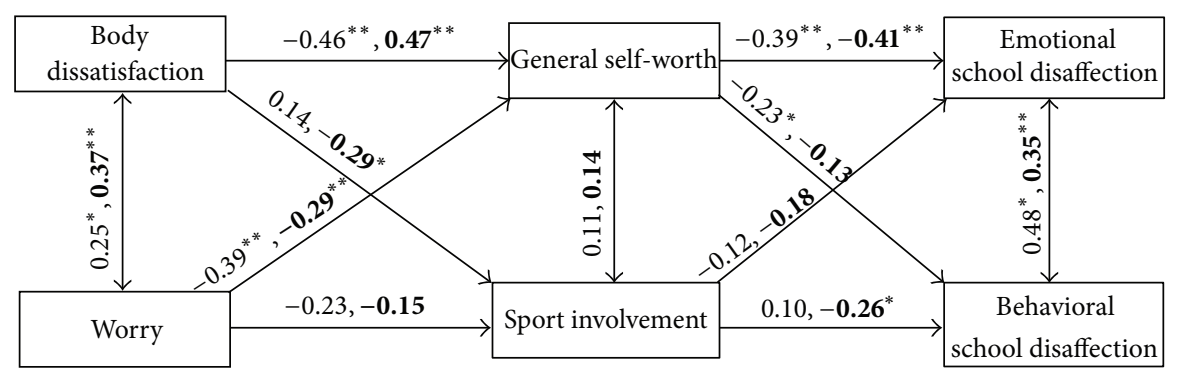

FIGURE 2: Gender grouping of path analysis. Significant effects shown as standardized coefficients (betas) are noted with the symbol $\left({ }^{*} P<.05\right.$. $\left.{ }^{* *} P<.001\right)$. Coefficients for female are shown in normal font and coefficients for male are shown in bold.

disaffection through general self-worth $(B=.06, \beta=.10$, $\mathrm{SE}=.03,95 \% \mathrm{CI}[.02, .13])$, as well as of worry on behavioral school disaffection through general self-worth $(B=.06$, $\beta=.06, \mathrm{SE}=.03,95 \%$ CI $[.02, .13])$. In contrast, sport involvement did not mediate the associations between school disaffection, body dissatisfaction, and worry.

These findings suggest that general self-worth plays a key role in the association between school disaffection and body dissatisfaction as well as for feelings of worry. In other words, high general self-worth functions as a protective factor for negative emotions and attitudes. In contrast, playing sport does not function as a mediator (all 95\% CIs contain zero).

10.3. Multigroup Comparison. A multi-group comparison was used to assess whether there are gender-specific differences in the indirect pathways described above. The fit indices for the gender model as recommended by $\mathrm{Hu}$ and Bentler [95] were good (see Table 4). The findings of our analysis are shown in Figure 2. By way of a chi-square difference test, this multi-group model was compared to the baseline model $\left(\chi^{2}(4)=4.19, P=.38\right)[98]$. The $P$ value indicates that the multi-group model was favored as opposed to the baseline model, hence the model that included the gender differences showed a better fit to the data indicating essential gender differences $[94,99]$.

10.3.1. Direct Effects. The model included the same direct paths as the baseline model described above, separated by gender. Significant direct effects could be shown in almost every path on general self-worth for both girls and boys, except the path from behavioral school disaffection to general self-worth for boys $(B=-.13, \beta=-.18, \mathrm{SE}=.12, P=.30)$. The paths to and from sport involvement are almost all nonsignificant, except the paths from playing sport to body dissatisfaction for boys $(B=-.09, \beta=-.29, \mathrm{SE}=.04, P=.02)$ and from behavioral school disaffection to sport involvement, again for boys $(B=-.63, \beta=-.26, \mathrm{SE}=.27, P=.02)$. These results demonstrate that sport involvement might decrease body dissatisfaction and behavioral school disaffection for boys, but not for girls. For girls, general self-worth plays a more important role as a mediator.

As with the baseline model, the zero order correlations between the predictors and outcome variables were found to be significant, however no significant relationship was found between the mediators.
10.3.2. Indirect Effects. Four significant indirect pathways were identified for girls and boys. Gender differences could also be identified in the model. For instance, there were indirect effects of body dissatisfaction and worry on school disaffection for girls, which were assessed through general self-worth, and no indirect effects for the mediator of sport involvement. The strongest effects were found for body dissatisfaction on emotional school disaffection mediated by general self-worth $(B=.11, \beta=.18, \mathrm{SE}=.04,95 \% \mathrm{CI}[.05, .19])$ and of worry on emotional school disaffection through general self-worth $(B=.13, \beta=.15, \mathrm{SE}=.04,95 \% \mathrm{CI}[.06, .23])$. Weaker effects were observed for body dissatisfaction on behavioral school disaffection through general self-worth $(B=.07, \beta=.10, \mathrm{SE}=.04,95 \% \mathrm{CI}[.01, .14])$ and of worry $(B=.08, \beta=.09, \mathrm{SE}=.04,95 \% \mathrm{CI}[.00, .16])$.

In contrast, two of the four significant indirect effects in the boys group were mediated by sport involvement: (1) the path of body dissatisfaction on emotional school disaffection $(B=.04, \beta=.05, \mathrm{SE}=.03,95 \% \mathrm{CI}[.00, .11])$ and (2) the path of body dissatisfaction on behavioral school disaffection $(B=.05, \beta=.08, \mathrm{SE}=.03,95 \% \mathrm{CI}[.01, .14])$. Thus, sport involvement has a greater impact on body dissatisfaction for boys than for girls. Similar to the female group, the strongest indirect effect was found for body dissatisfaction on emotional school disaffection through general self-worth $(B=$ $.14, \beta=.20, \mathrm{SE}=.04,95 \% \mathrm{CI}[.08, .25])$. Another significant path was found for emotional school disaffection via general self-worth on worry $(B=.13, \beta=.12$, $\mathrm{SE}=.07,95 \%$ CI $[.03, .31])$. The weaker indirect effects of body dissatisfaction are mediated by playing sport: (1) the first path on emotional school disaffection $(B=.04, \beta=.05, \mathrm{SE}=.03,95 \%$ CI $[.00, .11])$. and (2) the second path on behavioral school disaffection $(B=.05, \beta=.08, \mathrm{SE}=.03,95 \% \mathrm{CI}[.01, .14])$.

In general, the variable of sport involvement only functioned as a mediator for boys. For boys, the analysis assessed one path on behavioral school disaffection and three on emotional school disaffection. Conversely, the model explained two paths on emotional school disaffection as well as two paths on behavioral school disaffection for girls.

The identified final multi-group mediation model explained about $17 \%$ of the variance of emotional school disaffection in the female group $\left(R^{2}=0.173\right)$ and about $25 \%$ in the male group $\left(R^{2}=0.250\right)$. Furthermore, the final model explained about $6 \%$ of the variance of behavioral school disaffection in the female group $\left(R^{2}=0.056\right)$ and about $11 \%$ 
in the male group $\left(R^{2}=0.109\right)$. The explained variance in both groups was the highest for general self-worth $\left(R_{\text {female }}^{2}=\right.$ .447, $\left.R_{\text {male }}^{2}=407\right)$. Overall, the model fits better for boys than for girls.

\section{Discussion}

In accordance with Reschly et al. [12] and based on the reverse of Frederickson's broaden and build theory, the main goal of the present study was to examine if negative emotions and thoughts, specifically worry and body dissatisfaction, are associated with school disaffection in preadolescence. Additionally, general self-worth and sport involvement have been tested as mediators in these associations in order to identify possible starting points for prevention and intervention.

In general, the results of the correlation analysis supported the first hypothesis that there is a positive association between body dissatisfaction, worry, and school disaffection. These results are in line with Reschly and colleagues [12] who found that in a sample of secondary students, negative emotions are associated with lower levels of school engagement. Furthermore, the positive correlation between body dissatisfaction, worry, and school disaffection supports the reverse of Frederickson's broaden and build theory; such as frequent negative emotions (e.g., worry) may constrain humans' thoughts and behaviors. Future longitudinal research will be necessary to prove this assumption in detail.

For the whole sample, sport involvement was related negatively to emotional school disaffection, whereas general self-worth was related negatively to emotional and behavioral school disaffection. In addition, both general self-worth and sport involvement were negatively associated with worry. In addition, the results of the correlation analysis have shown that boys tend to engage more often in sport activities than girls and feel less worried. These findings are in accordance with research on gender differences in sport involvement (e.g., [100]) and emotional mood in preadolescence (e.g., [101, 102]). However, it should be noted that the results of the correlation analysis did not suggest any evidence for gender differences in body dissatisfaction, general self-worth, and school disaffection. These findings are in contrast to those of Ricciardelli and McCabe [29] and Schur et al. [103] who found that girls between 6 and 8 years of age show higher levels of dissatisfaction with their bodies than boys and a greater desire to be thin (see also [5-7, 21, 41]).

In line with the second hypothesis, body dissatisfaction and worry negatively predict general self-worth for both boys and girls. These results contradict the findings from studies with older children indicating that physical appearance and associated body satisfaction play a greater role in female than in male adolescents' self-worth [104, 105]. Interestingly, body dissatisfaction functions as a negative predictor on sport involvement solely for boys. Against our hypothesis, worry did not predict sport involvement at all. In addition, general self-worth and sport involvement were tested as negative predictors of school disaffection. The findings underline the essential role of general self-worth, which negatively predicts emotional school engagement (for boys and girls) and behavioral school disaffection (only for girls). In contrast, sport functions as a negative predictor of behavioral school disaffection for boys only.

The third hypothesis could be confirmed partially in that indirect effects of body dissatisfaction and worry on school disaffection were assessed through general self-worth for both boys and girls. In detail, the strongest effects for girls could be identified for body dissatisfaction on emotional school disaffection, mediated by general self-worth. Another strong effect was found for worry on emotional school disaffection through general self-worth. The indirect effects of body dissatisfaction on behavioral school disaffection through general self-worth and of worry were weaker but significant. In contrast, sport involvement did not function as mediator at all for girls. For boys, both general self-worth and sport involvement function as mediators in the association between body dissatisfaction, worry, and school disaffection. Similar to the female group, the strongest indirect effects were found for body dissatisfaction and worry on emotional school disaffection through general self-worth. Weaker indirect effects could be identified for body dissatisfaction on emotional and behavioral school disaffection through sport involvement. In general, this finding is consistent with the results of Gadbois and Bowker [106] who report that sport participation has been shown to be more important for the well-being among males than females.

Taken together, the findings extend the literature by demonstrating an association between body dissatisfaction, worry, and school disaffection mediated by sport involvement and general self-worth. A major contribution of the present study was the implications of the findings for prevention and intervention strategies for body dissatisfaction in preadolescence. As students spend a huge amount of time during their late childhood and adolescence in school, school psychologists and school professionals bear a strong responsibility to advance the emotional and behavioral well-being of preadolescent males and females. For boys, playing sport appears to be a useful behavioral dimension that can be easily implemented in daily school life. Studies have demonstrated that playing sport benefits not only the physical development but also the emotional well-being of children [70]. Children who regularly play sport are less likely to receive negative attention for misbehaving [72]. In addition, physical activities are able to decrease depressive symptoms [77] and have positive effects on school achievement [78]. For both boys and girls, general self-worth has been identified as an effective mediator in the association of body dissatisfaction, worry, and school disaffection. This finding supports the idea that global self-worth is usually a central parameter in psychological health and positive development [69], although there are competing perspectives [107].

In general, our findings illustrate that the increasing societal interest in male body ideals is not likely to come without negative psychological consequences for boys and men [108] as no evidence for gender differences in body dissatisfaction could be identified. Thus, it is necessary to prevent the development of body dissatisfaction in girls and boys as early in their development as possible. 
11.1. Strength, Limitations, and Future Research. As with all research, the findings of the present study should be interpreted in the light of a number of limitations. First, the sample size was relatively small, which may have limited the power of some analyses. Replication of these findings with a larger, more representative population would be imperative. Second, one may criticize the use of single item measures for worry and sport involvement. However, research has shown that single item measures have been used effectively to assess mood and emotional states $[109,110]$ as well as unambiguous constructs [111], such as the bipolar information (yes or no) about having done sport during the last week. Furthermore, the test-retest reliability of both worry and sport involvement was statistically satisfying. Third, all of the measures were based on self-report questionnaires. However, according to Chan [112], the negative attitude towards self-report data has taken unjustified proportions (see also Spector [113]), which we wish to counteract with this study. Although the focus of this study was on the perceptions of the students, those of other family members and peers should also be included in future research to obtain converging evidence [114, 115]. Finally, the correlational nature of the study means that firm conclusions about the causal ordering of variables cannot be definitively established. Future researchers may wish to utilize a prospective design to investigate the individual and additive effects of familial and peer modeling, rather than the crosssectional design used here. In addition, future studies need to investigate younger samples in order to determine the age at which body dissatisfaction and its influence on school disaffection first appears. Furthermore, gender-specific longitudinal studies from childhood through adolescence are required to identify the developmental structure in the interplay of worry, body dissatisfaction, and school disaffection.

Despite these limitations, the present study has extended the existing research on body dissatisfaction and worry in preadolescence by including the school context, and in particular, school disaffection. While most studies focus on adolescent girls' body dissatisfaction in association with the development of eating disorders, the present study focused on both girls' and boys' body dissatisfaction and worry, in nonclinical samples of preadolescents. Our findings provide important evidence that body dissatisfaction and worry are existing phenomena in preadolescence amongst girls and boys. Taken together, SEM confirmed that there is an association between body dissatisfaction, worry, and both emotional and behavioral school disaffection. Furthermore, the results of the $\chi^{2}$ difference test underlined essential gender differences in the interplay of these variables. In addition, a major contribution of the present study was the implications of the findings for prevention and intervention strategies for body dissatisfaction in late childhood preadolescence; whereas general selfworth was identified as a mediator for boys and girls, playing sport functioned as a mediator for boys only. These data and future findings will help school health professionals and educators devise gender-specific programming in their curricula or adapt existing models $[15,116]$ pertaining to this issue.

\section{Acknowledgment}

The authors would like to thank the principals, teachers, and students for their cooperation in making these studies possible.

\section{References}

[1] Y. S. Scattolon and R. M. Nicki, "Worry as an inhibitor of dietary restraint," Behavioural and Cognitive Psychotherapy, vol. 23, no. 1, pp. 25-33, 1991.

[2] S. Sassaroli and G. M. Ruggiero, "The role of stress in the association between low self-esteem, perfectionism, and worry, and eating disorders," International Journal of Eating Disorders, vol. 37, no. 2, pp. 135-141, 2005.

[3] T. A. Wadden, G. Brown, G. D. Foster, and J. R. Linowitz, "Salience of weight-related worries in adolescent males and females," International Journal of Eating Disorders, vol. 10, no. 4, pp. 407-414, 1991.

[4] S. Sassaroli, S. Bertelli, M. Decoppi, M. Crosina, G. Milos, and G. M. Ruggiero, "Worry and eating disorders: a psychopathological association,” Eating Behaviors, vol. 6, no. 4, pp. 301-307, 2005.

[5] B. K. Mendelson, M. J. Mendelson, and D. R. White, "Bodyesteem scale for adolescents and adults," Journal of Personality Assessment, vol. 76, no. 1, pp. 90-106, 2001.

[6] K. Presnell, S. K. Bearman, and E. Stice, "Risk factors for body dissatisfaction in adolescent boys and girls: a prospective study," International Journal of Eating Disorders, vol. 36, no. 4, pp. 389401, 2004.

[7] E. Stice and K. Whitenton, "Risk factors for body dissatisfaction in adolescent girls: a longitudinal investigation," Developmental Psychology, vol. 38, no. 5, pp. 669-678, 2002.

[8] D. Raufelder, D. Jagenow, and A. Ittel, "Das Zusammenspiel von Mediennutzung, Freizeitverhalten und Körperzufriedenheit von Jungen und Mädchen in der früh-pubertären Entwicklungsphase," MERZ-Zeitschrift für Medienpädagogik, vol. 55, pp. 21-34, 2011.

[9] J. W. Alspaugh, "Achievement loss associated with the transition to middle school and high school," Journal of Educational Research, vol. 92, no. 1, pp. 20-25, 1998.

[10] B. L. Fredrickson, "What good are positive emotions?" Review of General Psychology, vol. 2, no. 3, pp. 300-319, 1998.

[11] B. L. Fredrickson, "The role of positive emotions in positive psychology: the broaden-and-build theory of positive emotions," American Psychologist, vol. 56, no. 3, pp. 218-226, 2001.

[12] A. L. Reschly, E. S. Huebner, J. J. Appleton, and S. Antaramian, "Engagement as flourishing: the contribution of positive emotions and coping to adolescents' engagement at school and with learning," Psychology in the Schools, vol. 45, no. 5, pp. 419-431, 2008.

[13] H. Hölling, R. Schlack, and B. M. Kurth, "Kinder-FamilienGesundheit: Fakten und Zahlen aus dem bundesweit repräsentativen Kinder- und Jugendgesundheitssurvey (KIGGS)," in Familienmedizin in Deutschland. Notwendigkeit, Dilemma, Perspektiven, J. Collatz, Ed., pp. 97-131, Pabst Science, Lengerich, Germany, 2010.

[14] J. L. Derenne and E. V. Beresin, "Body image, media, and eating disorders," Academic Psychiatry, vol. 30, no. 3, pp. 257-261, 2006.

[15] K. J. Kater, J. Rohwer, and K. Londre, "Evaluation of an upper elementary school program to prevent body image, eating, and 
weight concerns," Journal of School Health, vol. 72, no. 5, pp. 199-204, 2002.

[16] L. M. Irving and S. R. Berel, "Comparison of media-literacy programs to strengthen college women's resistance to media images," Psychology of Women Quarterly, vol. 25, no. 2, pp. 103111, 2001.

[17] J. I. Hudson, E. Hiripi, H. G. Pope Jr., and R. C. Kessler, “The prevalence and correlates of eating disorders in the National Comorbidity Survey Replication," Biological Psychiatry, vol. 61, no. 3, pp. 348-358, 2007.

[18] R. H. Striegel-Moorel and D. L. Franko, "Epidemiology of binge eating disorder," International Journal of Eating Disorders, vol. 34, pp. 19-29, 2003.

[19] T. D. Wade, A. Keski-Rahkonen, and J. Hudson, "Epidemiology of eating disorders," in Textbook in Psychiatric Epidemiology, M. Tsuang and M. Tohen, Eds., pp. 343-360, Wiley, New York, NY, USA, 3rd edition, 2011.

[20] G. D. Rosenblum and M. Lewis, "The relations among body image, physical attractiveness, and body mass in adolescence," Child Development, vol. 70, no. 1, pp. 50-64, 1999.

[21] S. Fisher, The Development and Structure of Body Image, Lawrence Erlbaum, Hillsdale, NJ, USA, 1986.

[22] A. Ittel and K. Drury, "The meaning of media and body issues of girls and boys," MERZ-Zeitschrift für Medienpädagogik, vol. 55, pp. 34-46, 2011.

[23] D. C. Jones, "Body image among adolescent girls and boys: a longitudinal study," Developmental Psychology, vol. 40, no. 5, pp. 823-835, 2004.

[24] M. Kostanski, A. Fisher, and E. Gullone, "Current conceptualisation of body image dissatisfaction: have we got it wrong?" Journal of Child Psychology and Psychiatry and Allied Disciplines, vol. 45, no. 7, pp. 1317-1325, 2004.

[25] H. G. Pope, D. L. Katz, and J. I. Hudson, "Anorexia nervosa and "reverse anorexia" among 108 male bodybuilders," Comprehensive Psychiatry, vol. 34, no. 6, pp. 406-409, 1993.

[26] R. Olivardia, H. G. Pope, J. J. Borowiecki, and G. H. Cohane, "Biceps and body image: the relationship between muscularity and self-esteem, depression, and eating disorder symptoms," Psychology of Men and Masculinity, vol. 5, no. 2, pp. 112-120, 2004.

[27] K. A. Phillips and R. D. Crino, "Body dysmorphic disorder," Current Opinion in Psychiatry, vol. 14, no. 2, pp. 113-118, 2001.

[28] T. C. Pickett, R. J. Lewis, and T. F. Cash, "Men, muscles, and body image: comparisons of competitive bodybuilders, weight trainers, and athletically active controls," British Journal of Sports Medicine, vol. 39, no. 4, pp. 217-222, 2005.

[29] L. A. Ricciardelli and M. P. McCabe, "Dietary restraint and negative affect as mediators of body dissatisfaction and bulimic behavior in adolescent girls and boys," Behaviour Research and Therapy, vol. 39, no. 11, pp. 1317-1328, 2001.

[30] K. C. Wood, J. A. Becker, and J. K. Thompson, "Body image dissatisfaction in preadolescent children," Journal of Applied Developmental Psychology, vol. 17, no. 1, pp. 85-100, 1996.

[31] F. Johnson and J. Wardle, "Dietary restraint, body dissatisfaction, and psychological distress: a prospective analysis," Journal of Abnormal Psychology, vol. 114, no. 1, pp. 119-125, 2005.

[32] D. R. McCreary and D. K. Sasse, "An exploration of the drive for muscularity in adolescent boys and girls," Journal of American College Health, vol. 48, no. 6, pp. 297-304, 2000.

[33] J. M. Seigel, "Body image change and adolescent depressive symptoms," Journal of Adolescent Research, vol. 17, pp. 27-41, 2002.
[34] E. Stice and S. K. Bearman, "Body-image and eating disturbances prospectively predict increases in depressive symptoms in adolescent girls: a growth curve analysis," Developmental Psychology, vol. 37, no. 5, pp. 597-607, 2000.

[35] P. K. Keel, J. A. Fulkerson, and G. R. Leon, "Disordered eating precursors in pre- and early adolescent girls and boys," Journal of Youth and Adolescence, vol. 26, no. 2, pp. 203-216, 1997.

[36] E. Stice, K. Presnell, and D. Spangler, "Risk factors for binge eating onset in adolescent girls: a 2-year prospective investigation," Health Psychology, vol. 21, no. 2, pp. 131-138, 2002.

[37] G. Cafri, J. K. Thompson, L. Ricciardelli, M. McCabe, L. Smolak, and C. Yesalis, "Pursuit of the muscular ideal: physical and psychological consequences and putative risk factors," Clinical Psychology Review, vol. 25, no. 2, pp. 215-239, 2005.

[38] K. K. Davison, C. N. Markey, and L. L. Birch, "A longitudinal examination of patterns in girls' weight concerns and body dissatisfaction from ages 5 to 9 years," International Journal of Eating Disorders, vol. 33, no. 3, pp. 320-332, 2003.

[39] J. A. Harriger, R. M. Calogero, D. C. Witherington, and J. E. Smith, "Body size stereotyping and internalization of the thin ideal in preschool-age girls," Sex Roles, vol. 63, no. 9-10, pp. 609620, 2010.

[40] D. M. McInerney and V. McInerney, Educational Psychology: Constructing Learning, Pearson, Sydney, Australia, 2006.

[41] D. Neumark-Sztainer, N. Falkner, M. Story, C. Perry, P. J. Hannan, and S. Mulert, "Weight-teasing among adolescents: correlations with weight status and disordered eating behaviors," International Journal of Obesity, vol. 26, no. 1, pp. 123-131, 2002.

[42] L. A. Ricciardelli, M. P. McCabe, and S. Banfield, "Body image and body change methods in adolescent boys role of parents, friends, and the media," Journal of Psychosomatic Research, vol. 49, no. 3, pp. 189-197, 2000.

[43] S. Grogan, Body Image: Understanding Body Dissatisfaction in Men, Women, and Children, Routledge, London, UK, 2008.

[44] R. M. Gardner, B. N. Friedman, and N. A. Jackson, "Body size estimations, body dissatisfaction, and ideal size preferences in children six through thirteen," Journal of Youth and Adolescence, vol. 28, no. 5, pp. 603-618, 1999.

[45] E. T. Barker and N. L. Galambos, "Body dissatisfaction of adolescent girls and boys: risk and resource factors," Journal of Early Adolescence, vol. 23, no. 2, pp. 141-165, 2003.

[46] H. E. Shaw, E. Stice, and D. W. Springer, "Perfectionism, body dissatisfaction, and self-esteem in predicting bulimic symptomatology: lack of replication," International Journal of Eating Disorders, vol. 36, no. 1, pp. 41-47, 2004.

[47] A. Furnham and A. Calnan, "Eating disturbances, self-esteem, reasons for exercising and body weight dissatisfaction in adolescent males," European Eating Disorders Review, vol. 6, pp. 58-72, 1998.

[48] G. H. Cohane and H. G. Pope Jr., "Body image in boys: a review of the literature," International Journal of Eating Disorders, vol. 29, no. 4, pp. 373-379, 2001.

[49] L. Ricciardelli and M. P. McCabe, "Pursuit of muscularity among adolescents," in The Muscular Ideal: Psychological, Social, and Medical Perspectives, J. K. Thompson and G. Cafri, Eds., pp. 199-216, American Psychological Association, Washington, DC, USA, 2007.

[50] T. D. Borkovec, "The nature, functions, and origins of worry," in Worrying: Perspectives on Theory, Assessment and Treatment, G. Davey and F. Tallis, Eds., pp. 5-33, Wiley, Chichester, UK, 1994. 
[51] E. R. Watkins, "Constructive and unconstructive repetitive thought," Psychological Bulletin, vol. 134, no. 2, pp. 163-206, 2008.

[52] T. D. Borkovec, W. J. Ray, and J. Stöber, "Worry: a cognitive phenomenon intimately linked to affective, physiological, and interpersonal behavioral processes," Cognitive Therapy and Research, vol. 22, no. 6, pp. 561-576, 1998.

[53] S. American Psychiatric Association, Diagnostic and Statistic Manual of Mental Disorders, American Psychiatric Association, Washington, DC, USA, 4th edition, 1994.

[54] T. D. Wade and M. Tiggemann, "The role of perfectionism in body dissatisfaction," Journal of Eating Disorders, vol. 1, article 2, 2013.

[55] R. W. Connell, "An iron man: the body and some contradictions of hegemonic masculinity," in Sport, Men and the Gender Order, M. Messner and D. Sabo, Eds., Human Kinetics Books, Champaign, Ill, USA, 1990.

[56] J. P. Connell and J. G. Wellborn, "Competence, autonomy, and relatedness: a motivational analysis of self-system processes," in Self Processes and Development. The Minnesota Symposium on Child Psychology, M. R. Gunnar and L. A. Sroufe, Eds., pp. 4377, Lawrence Erlbaum Associates, Hillsdale, NJ, USA, 1991.

[57] E. A. Skinner and M. J. Belmont, "Motivation in the classroom: reciprocal effects of teacher behavior and student engagement across the school year," Journal of Educational Psychology, vol. 85, no. 4, pp. 571-581, 1993.

[58] J. D. Finn, School Engagement and Students at Risk, Department of Education, National Center for Education Statistics, Washington, DC, USA, 1993.

[59] H. M. Marks, "Student engagement in instructional activity: patterns in the elementary, middle, and high school years," American Educational Research Journal, vol. 37, no. 1, pp. 153$184,2000$.

[60] G. G. Wehlage, R. A. Rutter, G. A. Smith, N. Lesko, and R. R. Fernandez, Reducing the Risk: Schools as Communities of Support, Falmer Press, Philadelphia, Pa, USA, 1989.

[61] J. D. Finn and D. A. Rock, "Academic success among students at risk for school failure," Journal of Applied Psychology, vol. 82, no. 2, pp. 221-234, 1997.

[62] B. K. Mendelson, D. R. White, and M. J. Mendelson, "Selfesteem and body esteem: effects of gender, age, and weight," Journal of Applied Developmental Psychology, vol. 17, no. 3, pp. 321-346, 1996.

[63] M. P. McCabe and L. A. Ricciardelli, "Sociocultural influence's on body image and body changes among adolescent boys and girls," Journal of Social Psychology, vol. 143, no. 1, pp. 5-26, 2003.

[64] S. Grogan and H. Richards, "Body image: focus groups with boys and men," Men and Masculinities, vol. 4, no. 3, pp. 219-232, 2002.

[65] B. Gentile, S. Grabe, B. Dolan-Pascoe, J. M. Twenge, B. E. Wells, and A. Maitino, "Gender differences in domain-specific selfesteem: a meta-analysis," Review of General Psychology, vol. 13, no. 1, pp. 34-45, 2009.

[66] K. C. Kling, J. S. Hyde, C. J. Showers, and B. N. Buswell, “Gender differences in self-esteem: a meta-analysis," Psychological Bulletin, vol. 125, no. 4, pp. 470-500, 1999.

[67] U. K. Moksnes, I. E. O. Moljord, G. A. Espnes, and D. G. Byrne, "The association between stress and emotional states in adolescents: the role of gender and self-esteem," Personality and Individual Differences, vol. 49, no. 5, pp. 430-435, 2010.
[68] K. Tahmassian and N. J. Moghadam, "Relationship between self-efficacy and symptoms of anxiety, depression, worry and social avoidance in a normal sample of students," Iranian Journal of Psychiatry and Behavioral Sciences, vol. 5, no. 2, pp. 91-98, 2011.

[69] T. Haugen, R. Säfvenbom, and Y. Ommundsen, "Physical activity and global self-worth: the role of physical self-esteem indices and gender," Mental Health and Physical Activity, vol. 4, no. 2, pp. 49-56, 2011.

[70] A. Steptoe and N. Butler, "Sports participation and emotional wellbeing in adolescents," The Lancet, vol. 347, no. 9018, pp. 1789-1792, 1996.

[71] R. Bailey, K. Armour, D. Kirk, M. Jess, I. Pickup, and R. Sandford, "The educational benefits claimed for physical education and school sport: an academic review," Research Papers in Education, vol. 24, pp. 1-27, 2009.

[72] S. J. Donaldson and K. R. Ronan, "The efects of sports participation on young adolescents' emotional well-being," Adolescence, vol. 41, no. 162, pp. 369-389, 2006.

[73] K. R. Fox, "Self-esteem, self-perceptions and exercise," International Journal of Sport Psychology, vol. 31, no. 2, pp. 228-240, 2000.

[74] K. R. Fox, "The effects of exercise on self-perceptions and selfesteem," in Physical Activity and Psychological Well-Being, S. J. H. Biddle, K. R. Fox, and S. H. Boutcher, Eds., pp. 88-118, Routhledge, London, UK, 2000.

[75] G. Parfitt, D. Markland, and C. Holmes, "Response to physical exertion in active and inactive males and females," Journal of Sport and Exercise Psychology, vol. 16, pp. 178-186, 1994.

[76] J. Gordon and G. Grant, How We Feel, Jessica Kingsley, London, UK, 1997.

[77] C. Rothon, P. Edwards, K. Bhui, R. M. Viner, S. Taylor, and S. A. Stansfeld, "Physical activity and depressive symptoms in adolescents: a prospective study," BMC Medicine, vol. 8, article 32, 2010.

[78] P. A. Harrison and G. Narayan, "Differences in behavior, psychological factors, and environmental factors associated with participation in school sports and other activities in adolescence," Journal of School Health, vol. 73, no. 3, pp. 113-120, 2003.

[79] D. Sabo, K. Miller, M. Melnick, and L. Hey, Her Life Depends on It: Sport, Physical Activity and the Health and Well-Being of American Girls, Women's Sports Foundation, East Meadow, NY, USA, 2004.

[80] D. Sabo, M. Melnick, and B. Vanfossen, The Women's Sports Foundation Report: Minorities in Sports, Women's Sports Foundation, East Meadow, NY, USA, 1989.

[81] M. Pieron, C. Delfosse, and M. Cloes, "Effects of daily physical education programmes on the attitude of elementary school pupils," in Proceedings of the 10th Commonwealth and International Scientific Congress. Access to Active Living, F. I. Bell and G. H. Ghyn, Eds., pp. 440-444, Victoria, Canadaa, 1994.

[82] H. W. Marsh and S. Kleitman, "School athletic participation: mostly gain with little pain," Journal of Sport and Exercise Psychology, vol. 25, no. 2, pp. 205-228, 2003.

[83] McCreary Centre Society, Healthy Youth Development: Highlights from the 2003 Adolescent Health Survey, McCreary Centre Society, Vancouver, Canada, 2004.

[84] Z. Wang, N. M. Byrne, J. A. Kenardy, and A. P. Hills, "Influences of ethnicity and socioeconomic status on the body dissatisfaction and eating behaviour of Australian children and adolescents," Eating Behaviors, vol. 6, no. 1, pp. 23-33, 2004. 
[85] P. Gibbons, "The relationship between eating disorders and socioeconomic status: it's not what you think," Nutrition Noteworthy, vol. 4, no. 1, 2001, http://escholarship.org/uc/item/ $1 \mathrm{k} 70 \mathrm{k} 3 \mathrm{fd}$.

[86] D. M. Garner, M. P. Olmstead, and J. Polivy, "Development and validation of a multidimensional eating disorder inventory for anorexia nervosa and bulimia," International Journal of Eating Disorders, vol. 2, no. 2, pp. 15-34, 1983.

[87] S. Harter, "The perceived self competence scale for children," Child Development, vol. 53, pp. 87-97, 1982.

[88] E. Skinner, C. Furrer, G. Marchand, and T. Kindermann, "Engagement and disaffection in the classroom: part of a larger motivational dynamic?" Journal of Educational Psychology, vol. 100, no. 4, pp. 765-781, 2008.

[89] L. K. Muthén and B. O. Muthén, Mplus User's Guide, Muthén \& Muthén, Los Angeles, Calif, USA, 6th edition, 2012.

[90] K. J. Preacher and A. F. Hayes, "Asymptotic and resampling strategies for assessing and comparing indirect effects in multiple mediator models," Behavior Research Methods, vol. 40, no. 3, pp. 879-891, 2008.

[91] K. J. Preacher and A. F. Hayes, "Contemporary approaches to assessing mediation in communication research," in The Sage Sourcebook of Advanced Data Analysis Methods for Communication Research, A. F. Hayes, M. D. Slater, L. B. Snyder, A. F. Hayes, M. D. Slater, and L. B. Snyder, Eds., pp. 13-54, Sage, Thousand Oaks, Calif, USA, 2008.

[92] D. P. MacKinnon, Introduction to Statistical Mediation Analysis, Erlbaum, Mahwah, NJ, USA, 2008.

[93] O. Christ and E. Schlüter, Strukturgleichungsmodelle mit Mplus. Eine praktische Einführung, Oldenbourg, München, Germany, 2012.

[94] C. Geiser, Datenanalyse mit Mplus. Eine anwendungsorientierte Einführung, VS, Wiesbaden, Germany, 1st edition, 2010.

[95] L. Hu and P. M. Bentler, "Cutoff criteria for fit indexes in covariance structure analysis: conventional criteria versus new alternatives," Structural Equation Modeling, vol. 6, no. 1, pp. 1-55, 1999.

[96] L. K. Muthén and B. O. Muthén, Mplus User's Guide, Muthén \& Muthén, Los Angeles, Calif, USA, 6th edition, 1998-2012.

[97] P. E. Shrout and N. Bolger, "Mediation in experimental and nonexperimental studies: new procedures and recommendations," Psychological Methods, vol. 7, no. 4, pp. 422-445, 2002.

[98] A. Satorra and P. M. Bentler, "A scaled difference chi-square test statistic for moment structure analysis," Psychometrika, vol. 66, no. 4, pp. 507-514, 2001.

[99] K. E.-H. Yuan and P. M. Bentler, "On chi-square difference and $z$-tests in mean and covariance structure analysis when the base model is misspecified," Educational and Psychological Measurement, vol. 64, no. 5, pp. 737-757, 2004.

[100] M. Barnekow-Bergkvist, G. Hedberg, U. Janlert, and E. Jansson, "Physical activity pattern in men and women at the ages of 16 and 34 and development of physical activity from adolescence to adulthood," Scandinavian Journal of Medicine and Science in Sports, vol. 6, no. 6, pp. 359-370, 1996.

[101] C. Bisegger, B. Cloetta, U. von Rüden, T. Abel, and U. RavensSieberer, "Health-related quality of life: gender differences in childhood and adolescence," Sozial- und Präventivmedizin, vol. 50, pp. 281-291, 2005.

[102] P. M. Lewinsohn, M. Lewinsohn, I. H. Gotlib, J. R. Seeley, and N. B. Allen, "Gender differences in anxiety disorders and anxiety symptoms in adolescents," Journal of Abnormal Psychology, vol. 107, no. 1, pp. 109-117, 1998.
[103] E. A. Schur, M. Sanders, and H. Steiner, "Body dissatisfaction and dieting in young children," International Journal of Eating Disorders, vol. 27, pp. 74-82, 2000.

[104] A. Furnham, N. Badmin, and I. Sneade, "Body image dissatisfaction: gender differences in eating attitudes, self-esteem, and reasons for exercise," The Journal of psychology, vol. 136, no. 6, pp. 581-596, 2002.

[105] J. K. Thompson, L. J. Heinberg, M. Altabe, and S. TantleffDunn, Exacting Beauty: Theory, Assessment and Treatment of Body Image Disturbance, American Psychological Association, Washington DC, USA, 1999.

[106] S. Gadbois and A. Bowker, "Gender differences in the relationships between extracurricular activities participation, selfdescription, and domain-specific and general self-esteem," Sex Roles, vol. 56, pp. 675-689, 2007.

[107] R. F. Baumeister, J. D. Campbell, J. I. I. Krueger, and K. D. Vohs, "Does high self-esteem cause better performance, interpersonal success, happiness, or healthier lifestyles?" Psychological Science in the Public Interest, Supplement, vol. 4, supplement 1, pp. 1-44, 2003.

[108] A. Slater and M. Tiggemann, "Uncool to do sport': a focus group study of adolescent girls' reasons for withdrawing from physical activity," Psychology of Sport and Exercise, vol. 11, no. 6, pp. 619-626, 2010.

[109] R. E. Luria, "The validity and reliability of the Visual Analogue Mood scale," Journal of Psychiatric Research, vol. 12, no. 1, pp. 51-57, 1975.

[110] L. Zimmerman, B. Pozehl, K. Duncan, and R. Schmitz, "Effects of music in patients who had chronic cancer pain," Western Journal of Nursing Research, vol. 11, no. 3, pp. 298-309, 1989.

[111] J. P. Wanous, A. E. Reichers, and M. J. Hudy, "Overall job satisfaction: how good are single-item measures?" Journal of Applied Psychology, vol. 82, no. 2, pp. 247-252, 1997.

[112] D. Chan, "So why ask me? Are self-report data really that bad?" in Statistical and Methodological Myths and Urban Legends, C. E. Lance and R. J. Vandenberg, Eds., pp. 309-336, Routledge, New York, NY, USA, 2009.

[113] P. E. Spector, "Method variance in organizational research: truth or urban legend?" Organizational Research Methods, vol. 9, no. 2, pp. 221-232, 2006.

[114] A. Boeger, "Körper und Geschlecht im Jugendalter: Schlaglichter auf eine Entwicklungsaufgabe für beide Geschlechter," in Handbuch Psychologie und Geschlechterforschung, G. Steins, Ed., pp. 133-151, VS, Wiesbaden, Germany, 2010.

[115] H. Keery, K. Boutelle, P. van den Berg, and J. K. Thompson, "The impact of appearance-related teasing by family members," Journal of Adolescent Health, vol. 37, no. 2, pp. 120-127, 2005.

[116] R. R. Evans, J. Roy, B. F. Geiger, K. A. Werner, and D. Burnett, "Ecological strategies to promote healthy body image among children," Journal of School Health, vol. 78, no. 7, pp. 359-367, 2008 . 

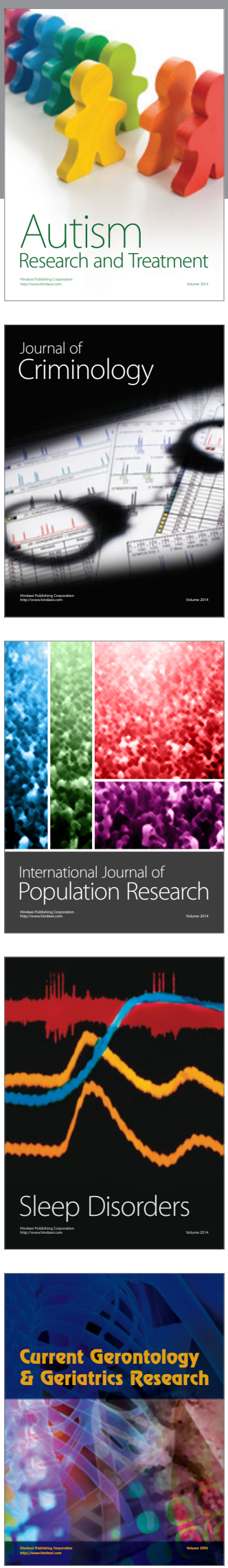
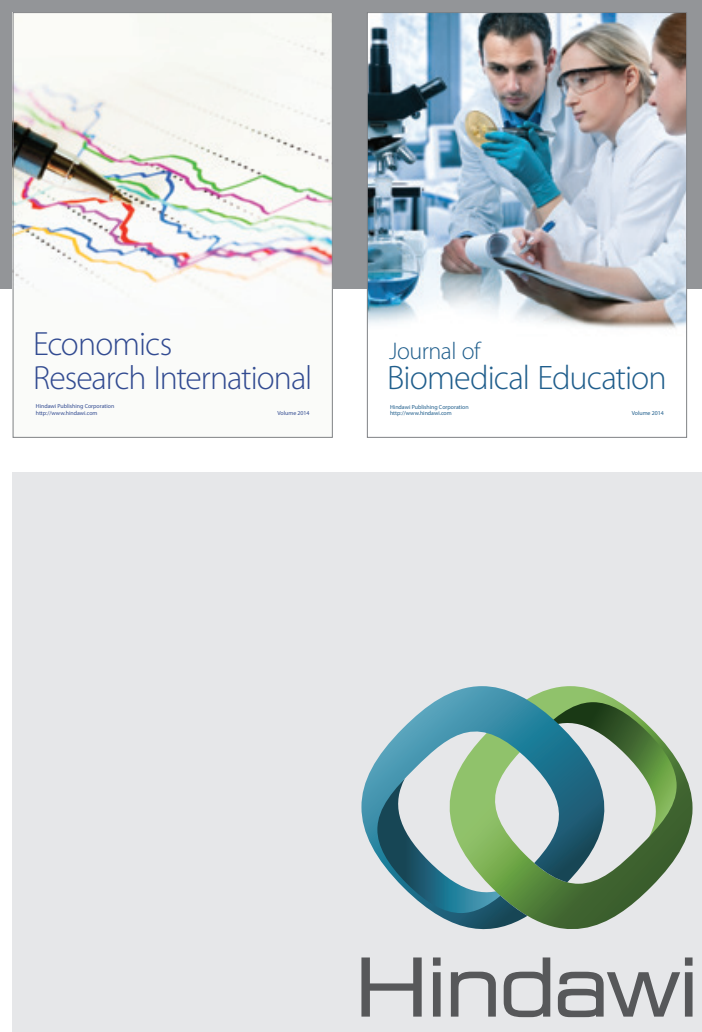

Submit your manuscripts at

http://www.hindawi.com
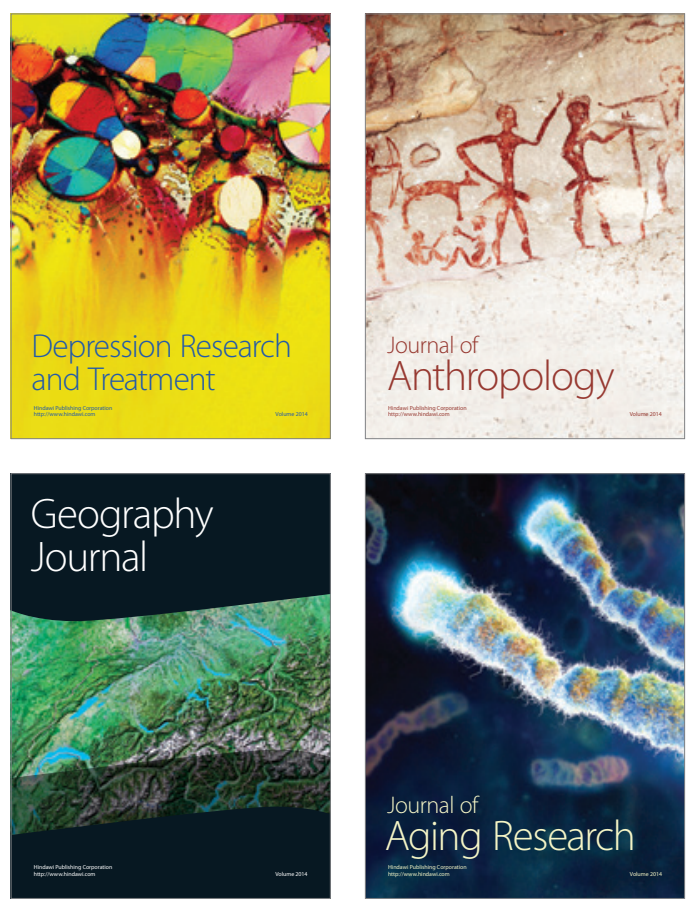
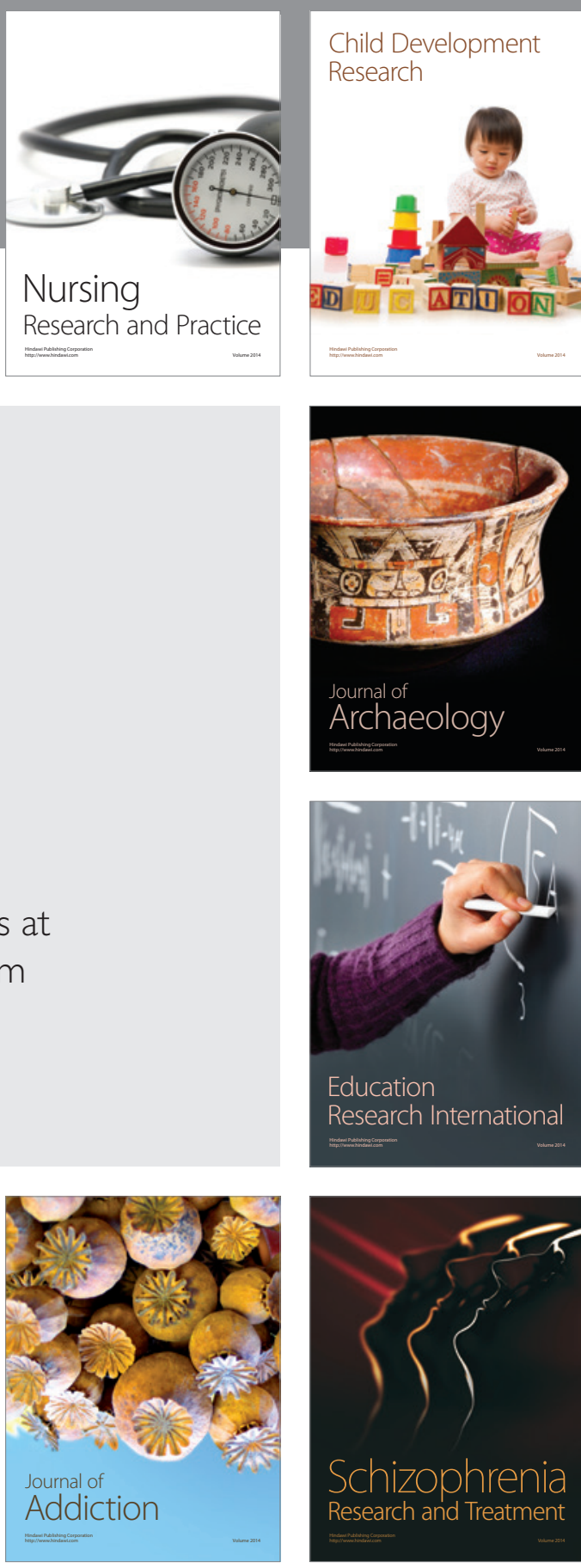

(D)
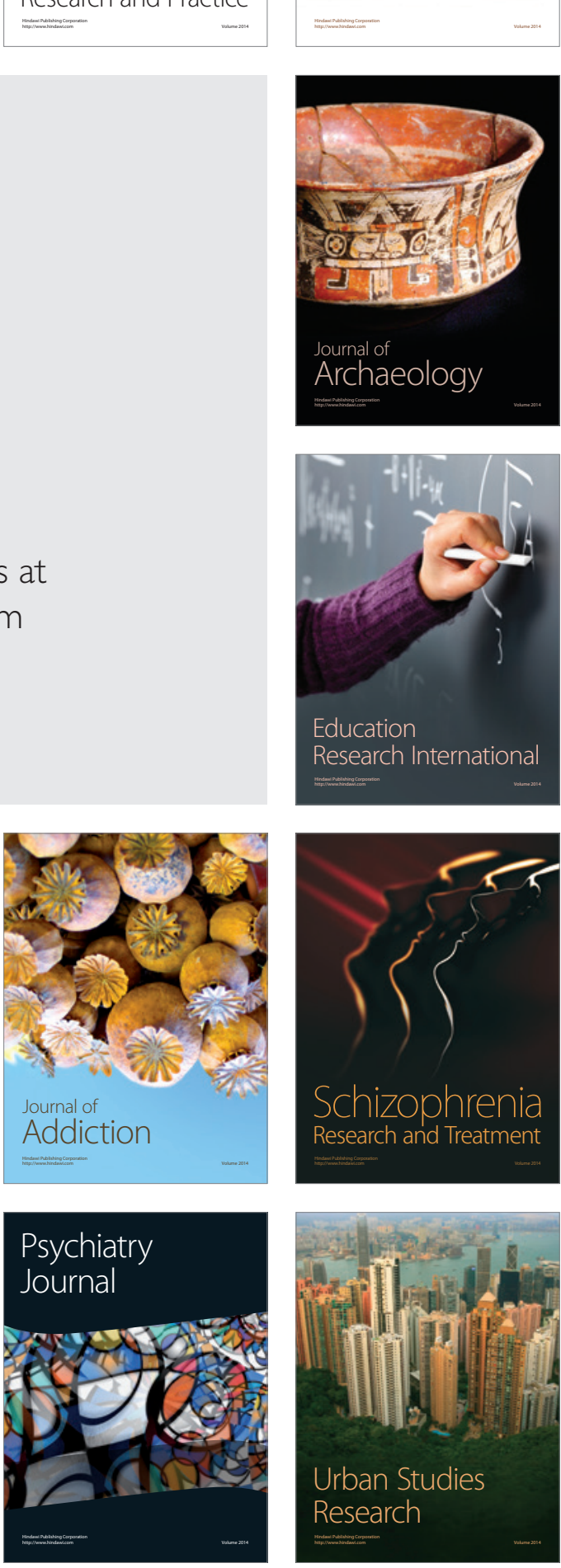